\title{
O sexual, a sexualidade e suas apresentações na atualidade
}

The sexual, sexuality and its presentations in contemporaneity

\author{
Paulo Roberto Ceccarelli*1 \\ Eduardo Lucas Andrade*2
}

\begin{abstract}
O texto discute as apresentações do sexual na atualidade. Inicialmente, os autores fazem uma breve digressão evolutiva da sexualidade e como, a partir dos aportes de Freud e Ferenczi, entre outros, tanto o sexual quanto a sexualidade tomaram caminhos inusitados no humano. Discute-se também as duas dimensões, no sentido quântico, com as quais a psicanálise trabalha mostrando, em seguida, como a contemporaneidade repete, com cópias diferentes, o conservadorismo pulsional, fazendo com que a história dos seres humanos seja um eterno recomeçar. Finalmente, debate-se como, na contemporaneidade, os discursos sobre a sexualidade continuam tributários da moral sexual cultural em suas tentativas de controlar o sexual.
\end{abstract}

Palavras-chave: O sexual, a sexualidade, discurso, atualidade

*1 Universidade Federal de Minas Gerais - UFMG (Belo Horizonte, MG, Brasil).

*2 Membro EBEP - Espaço Brasileiro de Estudos Psicanalíticos (Belo Horizonte, MG, Brasil). 
O que descrevemos como o "caráter" de uma pessoa é construído em grande parte com o material de excitações sexuais, e se compõe de pulsões fixadas desde a infância, de construções alcançadas por meio da sublimação, e de outras construções, empregadas para eficazmente conter os impulsos perversos que foram reconhecidos como inutilizáveis.

Freud, 1905

\section{Introdução}

A reprodução sexuada começou há milhões de anos, representando uma das adaptações evolutivas mais bem-sucedida: é por meio dela que a vida, em suas mais variadas formas e cuja origem continua desconhecida, se transmite. Desde a primeira fusão primordial de matéria até o desenvolvimento impressionante da infinita diversidade de manifestações da vida, centenas de milhões de anos se passaram.

Há aproximadamente cinco ou seis milhões de anos, o ancestral do homem se separou do conjunto dos primatas. Levando-se em conta que o DNA do homem tem $99 \%$ em comum com os bonobos e os chimpanzés, podemos supor que, em um primeiro momento, nosso ancestral não apresentasse uma sexualidade muito diferente de seus parentes próximos.

Entretanto, em determinado momento evolutivo, há aproximadamente dois milhões de anos, uma modificação radical ocorreu: a aquisição da posição bípede que, dando origem ao Homo erectus, permitiu um desenvolvimento sem igual do cérebro. Como consequência, teria ocorrido, segundo Freud, uma diminuição dos estímulos olfativos por meio dos quais o processo menstrual atuava sobre a psique masculina. Seu papel foi assumido pelos estímulos visuais que, ao contrário dos estímulos olfativos intermitentes, podiam conservar um efeito permanente (Freud, 1930/2016, pp. 105-106). 


\section{ARTIGOS}

Com a aquisição da posição bípede, adveio o Recalque Orgânico, que afetou a sexualidade a tal ponto, que sua satisfação completa ficou impedida. Tudo isso levou a sublimações e deslocamentos libidinais em relação ao objeto, em oposição à "sua primitiva existência animal" (Freud, 1930/2016, pp. 116-117).

A separação da sexualidade humana do programa biológico é tributária das agruras produzidas por mudanças climáticas devido a uma era glacial. Essa é uma das teses apresentadas por Freud em um de seus textos mais polêmicos, cujas consequências aguardam considerações mais detidas: Neuroses de transferência: uma síntese (Freud, 1915/1987). ${ }^{1}$ Nesse texto, Freud se utiliza do mito de uma era glacial, que teria provocado uma catástrofe ecológica de proporções avassaladoras. ${ }^{2}$ As transformações ocorridas no meio-ambiente tiveram repercussões diretas e imediatas nas modalidades de satisfação dos impulsos (Triebe). ${ }^{3}$

Surge, então, o aparelho psíquico (seelischer Apparat) que é psicopatológico em sua origem: uma organização para defender o organismo contra o excesso de phatos (de impulsos): os externos, as transformações do meio ambiente, e os internos, as demandas de moções de impulso que não podiam mais serem satisfeitas (Berlinck, 1998; 1999).

Ademais, para que a sobrevivência fosse garantida, teria ocorrido uma evolução psíquica que mudou radicalmente a forma de satisfação do impulso constante (Trieb). Essa evolução está intimamente ligada à noção de Anlehnung (apoio/anaclítico): o impulso sexual que estava atrelado, apoiado,

${ }^{1}$ Em 1983, quando se preparava a publicação da correspondência Freud-Ferenczi, Ilse Grubrich-Simitis encontrou um manuscrito que continua, no verso da última folha, uma carta de Freud a Ferenczi. Nela, Freud se refere a esse manuscrito como sendo o último dos 12 ensaios de uma série de artigos intitulados "Para preparar uma metapsicologia" (Zur Vorbereitung einer Metapsychologie). O texto "Übersicht der Übertragungsneurosen" (Visão geral das neuroses de transferência) escrito em 1915, recebeu em português uma má tradução: Neurose de transferência: uma síntese, tendo sido publicado pela Imago em 1987.

${ }^{2}$ Ferenczi (1924), de forma mais abrangente se lança, nesta mesma linha de escuta.

${ }^{3}$ Não entraremos na celeuma da tradução do termo alemão Trieb. Remetemos o leitor interessado ao texto "Retorno à querela do Trieb: por uma tradução freudiana" (Ramos Estevão, 2012). Seguimos Renato Zwick, em sua tradução de "O mal-estar na cultura", que traduz Trieb por impulso. Parece-nos que impulso se aproxima mais do verbo alemão Treiben: impelir, impulsionar (Cf. Freud, 1930/2016, p. 49, nota 5). 
à autoconservação, se desprende desta tomando outros caminhos (Freud, 1905/1976a). É o mesmo processo, segundo Roudinesco \& Plon (1998), que participa da escolha de objeto do amor no desenvolvimento psicossexual. O objeto que o satisfaz deixou de ser predeterminado, posto que o impulso não era mais natural (Naturtrieb), dando lugar a outra modalidade de satisfação, cujo objeto não tem nenhuma predeterminação: "É provável que, de início, a pulsão sexual seja independente de seu objeto, e tampouco deve ela sua origem aos encantos deste" (Freud, 1905/1976a, p. 149). A única "exigência" é que o objeto permita a satisfação do impulso (Trieb), a fim de manter o mais baixo possível o nível de tensão no organismo (princípio do prazer/princípio de constância). Foi também naquela época, ainda segundo o texto Neuroses de transferência: uma sintese (Freud, 1915/1987), que teria surgido a linguagem, com a dimensão simbólica que lhe é própria: o som, que seria o natural, cede espaço à invenção psíquica da linguagem. A linguagem é um trabalho psíquico com os sons.

Essa "astúcia evolutiva" separou, também, a sexualidade da reprodução: a sexualidade humana não está a serviço da procriação, mas, sim, do prazer; ela é uma perversão do impulso natural (Naturtrieb). Isto faz com que nossa espécie seja a única e praticar atos sexuais sem que exista um estímulo biológico. A base dos atos sexuais humano tornou-se a fantasia. A fantasia é o verdadeiro estímulo sexual e esta foge às rédeas biológicas. No fundo as relações sexuais são feitas com a própria fantasia.

Inicia-se, aí, a saga do "tornar-se humano" que culmina com outro mito, "Totem e tabu" (Freud, 1913/1974a), quando teria ocorrido a introjeção da Lei, a interdição, via recalque, da sexualidade incestuosa, e o estabelecimento do Estado de Cultura. Todo esse processo levou a outro fenômeno notável que só ocorre na nossa espécie: o culto aos mortos. O mais antigo "cemitério" conhecido, um poço na Espanha contendo inúmeros esqueletos, data de 350 mil anos. No humano, sexualidade e morte (início e fim) tornaram-se fatos de culturas, sem nenhuma relação com uma suposta natureza.

\section{Sexualidade e cultura}

Ao pesquisarmos sobre a história da sexualidade, ou, ainda, das práticas sexuais, descortinamos um cenário curioso: o quanto essa história é repetitiva, para não dizer monótona (Gregersen, 1983). Exceto por algumas formas de perversão, encontramos em todas as culturas as mesmas expressões da sexualidade, assim como as chamadas "identidades sexuais". O que a cultura 


\section{ARTIGOS}

ocidental, com a sua tendência a patologizar as subjetividades que fogem aos padrões socialmente construídos, denomina de "desvios" — perversões, travestismos, transexualidades, bissexualidades, e até algumas décadas atrás as homossexualidades - podem ser observadas em todos os grupamentos humanos, inclusive em outras espécies animais (Bagemihl, 1999). As explicações, justificativas, aceitação e/ou condenação que as expressões da sexualidade recebem respondem à visão da sexualidade da cultura em questão, sobretudo de como ela é apresentada nos mitos de origem (Ceccarelli, 2012).

Além disso, a maneira como os diversos grupamentos humanos lidam com as manifestações da sexualidade está, basicamente, atrelada a dois movimentos que afetam regiões psíquicas distintas, e que na maioria das vezes são tratados como se fossem da mesma ordem: o recalque do sexual e a repressão da sexualidade. (Adiante, faremos uma diferenciação entre o sexual e a sexualidade.)

O primeiro movimento, o recalque (Verdrängung), diz respeito à barreira do incesto, que nos obriga a abandonar nossos primeiros objetos sexuais: "uma exigência cultural da sociedade" (Freud, 1905/1976a, 232). Presente em toda cultura, o recalque é condição inegociável para que ela exista; é o movimento que diferencia e organiza o humano.

Já a repressão ${ }^{4}$ (Unterdrückung) da sexualidade guarda profundas relações com a moral sexual e aos sistemas de valores que sustentam o imaginário social do qual emerge a moral vigente:

A influência prejudicial da civilização reduz-se principalmente à repressão nociva (die Schädlich Unterdrückung) da vida sexual dos povos (ou classes) civilizados através da moral sexual 'civilizada' que os rege. (Freud, 1908/1976b, p. 191)

Entretanto, sendo o imaginário uma construção sustentada pelos mitos de origem da cultura em questão, ele muda segundo a cultura, a época e os costumes: ele é sócio-histórico, logo político.

Nessa perspectiva, ao analisarmos os discursos sobre a sexualidade ao longo da história do Ocidente, constatamos que cada momento sócio-histórico produziu dispositivos que ditam as regras referentes ao uso da libido e aos prazeres do corpo (Foucault, 1984; 1985a; 1985b). O "saber" sobre a sexualidade visa regulá-la, determinando os desejos e as práticas sexuais "normais",

${ }^{4}$ Talvez não seja por acaso que no texto "Moral sexual civilizada e doença nervosa moderna" (Freud, 1908/1976b), a palavra utilizada é repressão (Unterdrückung) e não de recalque (Verdrängung) da sexualidade. 
as "patológicas", além de oferecer "cura" às últimas. Esse "saber", verdadeiro dispositivo de controle do corpo, da vida social e política, foi sendo construído e apresentado como uma revelação e/ou como uma verdade, seja ele ditado pela ordem religiosa, jurídica ou médica e, quase sempre, atrelado aos interesses do Estado (Ceccarelli \& Costa-Salles, 2010; Reis Santos \& Ceccarelli, 2010).

Foi assim que a segunda metade do século XIX assistiu ao nascimento do discurso psiquiátrico. Marcado por uma visão moralista e higienista, e em continuidade com as posições teológicas e jurídicas, o saber psiquiátrico traz para a ordem médica o poder de deliberar sobre as práticas sexuais normais e as "desviantes", hoje muito bem definidas e classificadas como parafilias no Manual Diagnóstico e Estatístico de Transtorno Mental (DSM-5), e na Classificação Internacional de Doenças (CID-10).

Logo nas primeiras linhas do célebre Psicopatia sexual, de Richard Freiherr von Krafft-Ebing (1895/1990), obra de referência para a sexologia, médicos e juízes, e extremamente inovadora para a época lemos: "a perenidade da raça humana é garantida por um poderoso impulso natural (Naturtrieb) que exige imperiosamente ser satisfeito" (p. 5). Ao transformar a sexualidade em uma função, o "estilo psiquiátrico de raciocínio" (Van Haute, 2017, p. 4) passou a observar, catalogar e qualificar as manifestações (da sexualidade) que não fossem "naturais" como "perturbações", ainda que na ausência de causas orgânicas específicas ou lesões neurológicas. O minucioso inventário das manifestações da sexualidade que se traçou na época, fez surgir novas e inusitadas formas de perversões (Krafft-Ebing, 1895/1990).

As práticas "contra a natureza", isto é, as que desviavam da função reprodutiva, subvertendo a ordem natural, eram, e continuam sendo, discutidas em uma perspectiva repressiva carregada de moralismo: os perigos do sexo solitário (masturbação), os efeitos do coito interrompido, e/ou de uma vida conjugal insatisfatória, uma atividade sexual excessiva... Não mais em nome da religião, mas dos bons costumes, da moral e, sobretudo, da saúde (tratamentos para os viciados em sexo), essa nova caça às bruxas, levou ao surgimento de dispositivos para regular e controlar a sexualidade e até mesmo curar as manifestações "desviantes", que ameaçavam a ordem vigente.

As "perversões" foram literalmente "criadas" pelos sexólogos da época (Foucault, 1985a). Evidentemente, as atividades sexuais "desviantes", cuja finalidade não fosse a reprodução, sempre existiram e, dependendo da sociedade, esses "desvios" foram considerados atentado ao pudor, pecado, pouca vergonha, sodomia e outros tantos adjetivos, sendo, como é o caso até hoje em alguns países, punidos com pena de morte. Mas o novo foi que 


\section{ARTIGOS}

essas atividades passaram a definir e classificar os indivíduos, fazendo de suas práticas sexuais um elemento central de suas identidades subjetivas; uma forma de subjetivação:

A sexualidade foi esmiuçada em cada existência, nos seus mínimos detalhes; foi desencavada nas condutas; perseguida nos sonhos, suspeitada por trás das mínimas loucuras, seguida até os primeiros anos da infância; tornou-se a chave da individualidade: ao mesmo tempo, o que permite analisá-la e o que torna possível constituí-la. (Foucault, 1985a, p. 137)

\section{Freud, o sexual e a sexualidade}

Freud toma um outro caminho. Partindo da premissa segundo a qual sexualidade humana é polimorficamente perversa, Freud (1905/1976a) se interessa pelos desvios da sexualidade "normal" (a que levaria à procriação), e questiona suas bases.

Acreditar que a sexualidade humana se baseie em um impulso natural (Naturtrieb) que estaria ausente na infância, só se manifestando na puberdade, sendo marcada por uma atração natural de um sexo pelo outro visando a reprodução é uma "fábula poética" (poetische Fabel) (Freud, 1905/1976a, p. 136). Não se trata simplesmente de um erro simples, mas "um equívoco de graves consequências, pois é o principal culpado de nossa ignorância de hoje sobre as condições fundamentais da vida sexual" (p. 177): a biologia, a moral, a religião e a opinião popular, se enganam a respeito de uma suposta "natureza" da sexualidade humana (Freud, 1905/1976a).

No ser humano, o impulso sexual (Sexualtrieb) é composto por impulsos parciais (Partialtrieben) que não servem originalmente à reprodução, mas, antes, à obtenção de prazer em partes do corpo, para além dos genitais. Posto que ela não tem objeto natural e muito menos fixo, a suposta primazia das zonas genitais é uma ficção (Freud, 1908/1976b). E é à sublimação, a capacidade da moção sexual de "trocar seu objetivo sexual original por outro, não mais sexual, mas psiquicamente relacionado com o primeiro", que devemos nosso acervo cultural de bens materiais e ideais (Freud, 1908/1976b, p. 197).

A leitura freudiana, profundamente inovadora e subversiva em relação ao sexual, ou melhor, ao impulso sexual (Sexualtrieb), transformou radicalmente a ordem sexual vigente, trazendo uma visão revolucionária para a compreensão da sexualidade humana. O conhecido Drei Abhandlungen zur Sexualtheorie traduzido por "Três ensaios sobre a teoria da sexualidade" 
(Freud, 1905/1976a) é, de fato, de uma teoria sobre o sexual (Sexualtheorie), e não de uma teoria da sexualidade — Geschlecht.

Um dos aspectos da famosa "ruptura freudiana" foi a formulação do inconsciente (Freud, 1915/1976d), que revelou a alteridade interna que desconhecemos. É nele que encontramos os impulsos sexuais, ou simplesmente o sexual: o sexual é polimorfo, múltiplo e perverso; é o recalcado por excelência, que se manifesta nas fantasias e nos devaneios, nos atos falhos e nas ocasiões quando somos surpreendidos pelo estranho (Das Unheimlich). Trata-se de impulsos antes do recalque, isto é, das vicissitudes do sexual infantil antes da construção dos diques (vergonha, asco, exigências estéticas), organicamente condicionado e fixado pela hereditariedade (Freud, 1905/1976a). Em sua busca anárquica, incessante e amoral de prazer, na qual a procriação está ausente e o objeto é que menos importa, tudo serve, embora nada satisfaça, para que a tensão diminua: a força do impulso é constante.

Entretanto, Freud (1921/1976e) vai ainda mais além ao mostrar uma dimensão do sexual até então insuspeitada: somos animais de horda com uma herança filogenética, e nos agrupamos em torno de um líder, que pode ser uma pessoa, uma causa, uma teoria, enfim, em torno daquilo que nos dá a ilusão de sermos amparados.

A noção de impulso (Trieb), enfim, condensa o biológico e o psíquico; eles traduzem a vida do corpo no psiquismo, constituindo o motor da vida psíquica, aquilo que a anima. No animal humano, os representantes ideativos dão vozes aos impulsos transformando o sexual em psicossexual (Ceccarelli, 2017a).

Os discursos que sustentam o "politicamente correto", e que têm levado aos movimentos reacionários e moralistas cada vez mais na atualidade, refletem, a nosso ver, o retorno de impulsos recalcados (pertencentes aos processos primários), que se revelam insuportáveis à moral vigente (processos secundários).

O sexual é o grande enigma do ser humano. Todo grupamento humano, ao ser interpelado pelo sexual, cria, dentro de suas referências sintagmáticas, dispositivos para lidar com as demandas dos impulsos: são os discursos sobre a sexualidade, verdadeiros artefatos culturais tributários do momento sócio-histórico do qual emergem. No entanto, tais discursos sempre falharam, pois o sexual resiste a qualquer forma de normatização ou controle: os discursos sobre a sexualidade, oriundos da moral sexual, são produtos dos processos secundários que jamais darão conta de regulamentar o primário.

O que chamamos de "sexualidade" nos informa sobre os destinos do sexual. A "história" desse "destino" começa antes do nascimento da criança, no 


\section{ARTIGOS}

lugar que ela ocupa no narcisismo daqueles/as que lhe deram o que chamamos "berço psíquico", quando de sua chegada ao mundo (Ceccarelli, 2007).

Com Freud, as manifestações do sexual, inclusive a perversa, se humanizam por constituir-se o núcleo mais profundo de cada um: "há sem dúvida algo inato na base das perversões, mas esse algo é inato em todos os seres humanos" (Freud, 1905/1976a, p. 174). As perversões "são blocos de construção da sexualidade humana de uma forma isolada e ampliada" (Von Haute, 2017, p. 5). Enfim, devido ao fato de o sexual ser dificilmente compatível com as exigências da civilização, ele se constitui muito mais uma fonte de mal-estar do que de felicidade (Freud, 1930/2016).

O que está em jogo não é a sexualidade em si, tal como a criança experimenta, mas do infantilismo da sexualidade, presentes nas reminiscências, responsável pela "criança" que Freud constrói através dos relatos de suas pacientes; daquilo que a transferência atualiza, e da observação que o sexual infantil "sexualiza" tudo que toca.

Liberados do programa biológico, marcado por objetos pré-determinados de satisfação, pelo instinto, os destinos dos impulsos sexuais (Sexualtriebes) no humano são sempre enigmáticos. Para eles, a psicanálise não dá uma resposta definitiva, pois os fatores em jogo são inúmeros e dependentes das histórias libidinais de cada um. Ao tornar-se um impulso (Trieb) sem objeto pré-determinado de satisfação, mas mantendo a mesma força (Drang) do (instinto), a Trieb, é representada no psiquismo pela fantasia, "desenhando na superfície do corpo uma geografia da excitação que desconsidera qualquer "primado do genial" (Andre, 2016, p. 116), sempre pronta a mudar de meta.

E quando as transformações da puberdade trazem o biológico de volta, ele é marcado pelo sexual infantil, cujas bases são múltiplas, fazendo com que o sujeito experimente as manifestações de sua sexualidade, sustentadas pelo sexual recalcado, como uma revelação, posto que suas raízes escapam à lógica dos processos secundários. O chamado "primado de genital" encobre outras dimensões de prazer sempre prontas a satisfazerem-se a qualquer preço.

A lógica dos processos primários e secundários nos auxilia a compreender porque a histórica "revolução sexual" dos anos 1960 deixou inalterado o conflito psíquico, como continuamos a observar nos nossos consultórios (frigidez, ejaculação precoce, disfunções diversas...), o que prova que não há "tratamento" sociopolítico para o sexual. A "liberação sexual" produziu, sem dúvida, uma desrepressão (processos secundários) da sexualidade imposta pela moral sexual vigente, que ditava uma sexualidade normativa aplicável a todos. Foi exatamente contra a normatização que incidiu a revolução sexual. 
Entretanto, tal desrepressão não foi acompanhada, como não poderia sê-lo, de um desrecalcamento (processos primários) da mesma:

Quanto mais perto se chega das perturbações mais profundas do desenvolvimento psicossexual, mais se destaca, de maneira inequívoca, a importância da escolha objetal incestuosa. Nos psiconeuróticos, grande parte da atividade psicossexual destinada ao encontro do objeto, ou a totalidade dela, permanece no inconsciente, em decorrência de seu repúdio da sexualidade. (Freud, 1905/1976a, p. 234)

\section{As duas dimensões psicanalíticas da "realidade"}

As relações e interações entre os processos primários e os secundários sugerem que a psicanálise trabalha com duas realidades, no sentido quântico da palavra.

Segundo a física quântica, "não existe uma passagem linear, contínua e discreta do mundo quântico ao [mundo] visível, o que faz com que a realidade seja uma construção" (Ceccarelli, 2009, p. 925). À medida que adentramos o universo subatômico, somos cada vez mais confrontados com vastos espaços vazios e a campos energéticos de pulsações elétrica, magnética, acústica e gravitacional. A ordem apoia-se no caos, e os objetos sólidos que nos cercam são, no fundo, compostos de vazio. Ferenczi (1924/2011) postula sobre a intrínseca relação da física com a psicanálise em seu ensaio sobre a teoria da genitalidade:

O físico, para nos fazer compreender os fenômenos próprios de sua ciência, é obrigado a compará-los a "forças", "atrações", "pulsões", "resistências", "inércia" etc., tudo coisas de que só temos conhecimento pelo lado psíquico. Entretanto, Freud também se viu na obrigação de colocar o funcionamento psíquico na dependência de processos tópicos, dinâmicos, econômicos, por conseguinte, de processos puramente físicos, sem o que não teria estado em condições de explicá-lo inteiramente. (p. 279)

A passagem do universo quântico para o cotidiano da realidade guarda semelhanças com as relações existentes entre os processos primários e os secundários. Em ambos os casos, a barra do recalque impede o acesso direto à matéria bruta que, via sublimação, sustenta nossas construções, isto é, os processos primários. Essas duas "realidades" têm leis próprias. As que regem os processos primários - deslocamento, condensação, atemporalidade etc. — são imutáveis desde que o homem existe: os impulsos sempre em busca de satisfação e sendo, 


\section{ARTIGOS}

constantemente, limitados pelo trabalho de cultura (Kulturarbeit), como bem o atesta o mal-estar. Trata-se da parte invariável da alma humana que data da origem da espécie, e é marcada pelo recalque (Freud, 1915/1974b). Aconteça o que acontecer, essa parte não muda. E quando se tenta modificá-la, como nos regimes totalitários que se esforçam para transformá-la pelo controle do desejo, os resultados, bem o sabemos, são catastróficos. É por isso que Freud diz que o primitivo do homem continua em nós (Freud, 1930/2016).

Já os processos secundários são as construções discursivas que utilizamos para nos deslocarmos no simbólico. Construções estas que apresentam leituras diferentes com o passar do tempo e em função da história. Trata-se da parte mutável das representações psíquicas, que varia segundo as épocas. Por exemplo, os movimentos em defesa dos direitos, casamento e adoção por pessoas do mesmo sexo, a despatologização das identidades trans, a utilização do nome social, para citar as mais recentes, provocaram mudanças discursivas que dão novas representações aos afetos produzindo variações das representações dos impulsos sem, contudo, afetar os processos primários.

A passagem do irrepresentável para a linguagem, do gozo para o desejo, é feita pelos mitos de origem, patrimônio fantasmático de uma cultura. Seus relatos constroem o caminho, sempre imaginário, através da barra do recalque ligando o processo primário ao secundário. Os mitos fundadores fazem a passagem da parte estável da alma humana para a metastável, dando sentido à realidade: eles narram como, "graças às façanhas dos Entes Sobrenaturais, uma realidade passou a existir" (Eliade, 1972, p. 11).

Enfim, existiria uma parte que, sob a égide dos processos primários permanece invariável; outra, sob a égide do secundário, que muda de acordo com o tempo, a cultura e a história. Quando nos aferramos à parte mutável e, mobilizados pelos afetos que as mudanças sociais produzem, vemos aí algo negativo, corremos no risco de criarmos um discurso normativo para que nada mude, ou um discurso que nos dá a impressão que não há saída, não há esperanças, de que vivemos um momento de violência único. Muitos psicanalistas pensam assim, e apresentam visões pessimistas sobre o futuro.

Ora, a condição humana é feita dessas duas realidades, como disse, no sentido quântico do termo; duas realidades que coexistem e que, de tempos em tempos, devemos reavaliar como uma influencia outra, no sentido dialético. Quanto à ideia de que estamos caminhando para um caos completo é um grande fantasma que assombra o homem desde sempre, como bem o mostra a história. Sempre houve, e há, aqueles que pensam que o fim do mundo está próximo. 
Sem dúvida, pode-se argumentar que o capitalismo cria a ilusão de que tudo é possível. Mas não é verdade, e nem todos pensam assim. Evidentemente, sempre houve aqueles que creem que tudo é possível, mas esta história é velha embora, é claro, uma liberdade do desejo produza novas representações de angústia. $\mathrm{O}$ avanço tecnológico oferece novos objetos aos impulsos apontando a máscara de avanço lá onde se repete a história: "os caminhos pulsionais estão fadados a dar uma aparência enganadora de serem forças tendentes à mudança e ao progresso, ao passo que, de fato, estão apenas buscando alcançar um antigo objetivo por caminhos tanto velhos quanto novos" (Freud, 1920/2006, p. 161).

Os expedientes capazes de oferecer representações aos impulsos pertencentes aos processos primários existem desde o momento em que o recalque fundou o inconsciente, e variam ao longo da história. O que muda na contemporaneidade são os suportes oferecidos pela cultura, pelos processos secundários. Por exemplo, a internet não cria, por si, comportamentos adictivos. Ela é apenas um meio contemporâneo utilizado para os mais diversos fins. Quando o seu uso se transforma em adicção atingindo o estatuto de sintoma, é por estar reproduzindo dinâmicas psíquicas preexistentes (Ceccarelli, 2017a).

Para Freud (1915/1976c), nem o progresso tecnológico, nem a aquisição de novos conhecimentos produzem progresso psíquico: os conflitos de gerações sempre existiram, e continuarão a existir; as experiências pessoais, os "conselhos" para se obter satisfação, ou evitar o sofrimento, não podem ser transmitidos, o que faz com que a história dos seres humanos seja um eterno recomeçar, como bem o mostra as relações afetivas.

\section{A atualidade da psicanálise}

Se "a psicologia individual é ao mesmo tempo e simultaneamente psicologia social" (Freud, 1921/1976e, p. 91), a vocação da psicanálise consiste em estar atenta às mudanças das representações [Vorstellung] do sexual na atualidade para, a partir daí, se perguntar como tais mudanças afetam seus conceitos teórico-clínicos e, ao mesmo tempo, as repercussões dessas mudanças nos processos de subjetivação.

Se um impulso só pode tornar-se objeto da consciência por meio de sua representação [Vorstellung], cabe perguntar de quais representações os "estímulos oriundos do interior do corpo" (Freud, 1915/2013, p. 25) se 


\section{ARTIGOS}

utilizam na contemporaneidade para alcançar a mente. Interessa-nos, pois, saber como o sexual do psiquismo (processos primários) tem se manifestado nas construções sintagmáticas que utilizamos para "lermos" o mundo (processos secundários).

Quando a psicanálise não segue as mudanças sociopolíticas, ela corre o risco de ter sua "autoridade social" questionada (Fassin, 2003). Foi o que aconteceu, por exemplo, no que diz respeito a alguns posicionamentos em relação à homoparentalidade. Os opositores mais radicais a essa organização familiar não foram os membros do clero, o que seria perfeitamente compreensível, mas alguns psicanalistas que insistem em defender que a configuração edipiana baseada no modelo da família da Viena de Freud, era a única produtora de subjetividades sadias (Roudinesco, 2015).

Da mesma forma, os movimentos pela despatologização das identidades trans, só foram possíveis graças às mudanças discursivas que mostram, se necessário ainda o fosse, que todo discurso sobre a sexualidade é sempre uma construção social, sem nenhuma ancoragem em uma suposta "natureza humana". Esse discurso responde a interesses sociopolíticos e econômicos do momento histórico e da cultura na qual emerge, com toda a sua vinculação à moral e à norma (Ceccarelli, 2017b). Não é por acaso que as reações às manifestações do sexual na contemporaneidade continuam tributárias da moral sexual que, com roupagens diferentes, continuam a atestar os conflitos entre os impulsos sexuais e os limites impostos à satisfação pela moral cultural (Freud, 1930/2016).

Quanto aos discursos sobre a sexualidade, eles continuam com o vigor de sempre em suas tentativas de controlar o sexual. Entretanto, não são mais ditados pela religião ou pela medicina, alegando uma ordem divina ou uma preocupação médica. Atualmente, no Brasil, os três discursos tentaram se unir: médico, jurídico e religioso. A força do avanço foi unir retrocessos com bancadas fundamentalistas que lutam para impor uma "reorientação sexual" como proposta da psicologia, fazendo assim, no âmbito jurídico, uma autorização ao que tem sido chamado de "cura gay". No fundo sabem da aberração que estão propondo. São sustentados pelas inúmeras variantes do "politicamente correto" nas quais o retorno de moções de impulso recalcadas e reprimidas ficam evidentes, pelas reações produzidas pelos fatos relatados. Não raro, um sentimento de revolta toma conta do grupo promovendo reações as mais inusitadas que, muitas vezes, em nada deixa a desejar à violência que está sendo denunciada. É nessa perspectiva que defendemos a hipótese segundo a qual da mesma forma que a neurose é o retorno do recalcado, "as 
perversões seriam o retorno, sob o modo perverso, do reprimido" (Ceccarelli, 2012, p. 65).

É impressionante como relatos de "abuso sexual", em todas as suas versões, tornaram-se moeda corrente: olhares duvidosos no elevador, toques além dos esperados na consulta médica ou dentária, ajudar uma criança em perigo, um encostar deslocado entre professor(a) e aluno(a), o modo como uma criança foi tocada no banho, o bullying em suas várias formas e outros tantos. Na área jurídica, o tema tem tomado proporções impressionantes. No dia 20 de novembro de 2015 o Conselho Regional de Psicologia de Minas Gerais realizou, em Belo Horizonte, o seminário "Psicologia Jurídica e Direitos Humanos Belo Horizonte". O objetivo do evento foi discutir a atuação do psicólogo na área jurídica. O número de denúncias de abuso perpetrado pelos pais em situação de litígio entre o casal subiu enormemente.

Esquecemo-nos, contudo, que a sexualidade humana é eminentemente traumática (McDougall, 1997), e que nossa vida sexual começa por uma situação de sedução através dos "significantes enigmáticos" (Laplanche, 1987). Ou, como bem o coloca de Freud nos "Três ensaios...":

A mãe provavelmente se horrorizaria se lhe fosse esclarecido que, com todas as suas expressões de ternura, ela está despertando a pulsão sexual de seu filho e preparando a intensidade posterior desta. Ela considera seu procedimento um amor "puro", assexual, já que evita cuidadosamente levar aos genitais da criança mais excitações do que as inevitáveis no cuidado com o corpo. Mas a pulsão sexual, como bem sabemos, não é despertada apenas pela excitação da zona genital; aquilo a que chamamos ternura um dia exercerá seus efeitos, infalivelmente, também sobre as zonas genitais. (Freud, 1905/1976a, p. 230)

Anos mais tarde na conferência XXXII sobre Feminilidade, Freud retoma o tema:

Aqui, a fantasia toca o chão da realidade, pois foi realmente a mãe quem, por suas atividades concernentes à higiene corporal da criança, inevitavelmente estimulou e, talvez, até mesmo despertou, pela primeira vez, sensações prazerosas nos genitais da menina. (Freud, 1933/1976f, p. 149)

Outro ponto que a psicanálise tem que se haver na contemporaneidade diz respeito às questões de gênero, que têm trazido desconfortos e incômodos para o arcabouço teórico da psicanálise.

Em sua obra de referência, Problemas de gênero - feminismo e subversão de identidade, Butler (2003) traz a biologia para o campo do social, e defende que não existiria uma identidade de gênero por trás das diversas 


\section{ARTIGOS}

expressões de gênero: tal "identidade" é performativamente constituída, por meio da repetição de atos, gestos, signos e outras séries de elementos que, por sua vez, reforçam a construção dos corpos masculinos e femininos, tal como os conhecemos. Para Butler, enfim, não existem "[...] relações de coerência e continuidade entre sexo, gênero, prática sexual e desejo" (p. 38).

Se o sexo é tão historicizável quanto o gênero, e responde às posições ideológicas e de poder (Butler, 1990/2003), como pensar o masculino e o feminino que, para a psicanálise, são calcados no biológico? Além disso, dizer "fálico" $x$ "castrado", "presença" $x$ "ausência" revela um discurso de valor que, de antemão, anula a diferença pura para valorizar um sexo (o que possui, o que não é castrado) em detrimento do outro (o que não possui, o castrado). Em outras palavras: que exista uma diferença anatômica é um fato, mas o discurso que surge a partir daí para falar dessa diferença, classificá-la e, enfim, usá-la como sustentação de teorias, terá sempre uma dimensão política. Bertini (2009) mostra que o sistema hegemônico da diferença entre os sexos serve, de fato, para apoiar a desigualdade entre os sexos através de um poderoso dispositivo simbólico. Várias outras questões necessitam ser pensadas: ao célebre "o que quer uma mulher", devemos acrescentar "o que quer um homem", pois a questão passou a ser como pensar a diferença de sexos, isto é, a partir do momento que o sexo passa a ser historicizado, há de se repensar os "destinos" do sexo em contraponto ao texto freudiano de 1925 "Algumas consequências psíquicas da distinção anatômica entre os sexos". Ainda nessa perspectiva, as fórmulas de sexuação propostas por Lacan seriam apenas uma dentre outras teorias sobre a diferença, mas não necessariamente $o$ modo universal de subjetivação. ${ }^{5}$ Seja como for, a categoria de gênero revela-se um operador importante; um potente auxiliar para pensarmos com novos parâmetros, os caminhos dos impulsos, e as relações entre corpo, sexo e as construções identitárias. Referente ao gênero, pelo recalque e repressão, os adultos não estão preparados para dar conta de abordar a temática e assim manquejam nas transmissões em casa, ruas, mídias e escola. Mais precisamente em 2015, no Brasil, veio à tona a polêmica da ideologia de gênero e escola. "Se os educadores estão com dificuldades nas questões sexuais, como poderão esclarecer as crianças se nem eles foram esclarecidos?" (Andrade, 2017, p. 84).

${ }^{5}$ Michel Tort faz observações muito interessantes e pertinentes sobre este ponto. (Cf. Tort, 2000). 
Na clínica, os psicanalistas tiveram que rever muitas de suas premissas teóricas. Quando o sujeito se define de modo que os universais do masculino e do feminino, assim com as relações sexo/gênero, são abaladas — os transgêneros, transexuais, sujeitos não binários, e outras tantas nomenclaturas que surgem a cada dia, e se fazem cada vez mais presentes em nossos consultórios - somos obrigados a pensar as novas formas de laços sociais daí advindas. Se, até bem pouco tempo, essas pessoas eram ouvidas como possuidoras de um distúrbio, de uma disforia - de identidade sexual, de gênero —, a partir dos novos aportes teóricos, nossas posições devem ser revistas: se, como vimos, o sexo não é natural e o gênero é performativo, não haveria nenhuma "patologia" quando um sujeito se diz sentir homem, mas identificado a um sistema performativo feminino. Da mesma forma, um transexual pode, após a cirurgia, adquirir os caracteres anatômicos femininos, e manter relações afetivo-sexuais com mulheres. Essas novas possibilidades de subjetivação levaram a uma revisão dos "critérios de diagnósticos" em geral, além de produzirem críticas pertinentes à noção lacaniana de estrutura perversa. ${ }^{6}$ Tudo isso nos levou a nos perguntarmos: quando classificamos ou diagnosticamos certas manifestações da sexualidade, quais critérios de "normalidade" sustentam nossas classificações?

\section{Considerações finais}

Para a psicanálise a sexualidade é sempre uma construção singular, e a maneira que o sujeito a experimenta, consciente, mas, sobretudo inconsciente, é o resultado de um longo processo identificatório tendo como enredo a dinâmica edípica protagonizada pelas escolhas de objetos, as quais são tributárias das vicissitudes dos impulsos. Trata-se de uma criação particular e única de Eros; uma solução no sentido matemático do termo: uma equação que

${ }^{6}$ Philippe Van Haute apresenta duras críticas à noção lacaniana de estrutura perversa. Para esse autor, uma tal abordagem reintroduz a ideia de "identidade diferencial" desconstruída por Freud. "Ao fazê-lo, seus aderentes arriscam cair em todo tipo de preconceitos morais e sociais que são subsequentemente apresentados como leis que estruturam a sexualidade [...] Desta maneira preconceitos sociais e morais tendem a ser imunizados da crítica e, no processo, eles adquirem um estatuto ideológico" (Cf. Van Haute, 2017, p. 3). 


\section{ARTIGOS}

comporta diferentes variantes - corpo, amor, desejo, gozo - frente às quais, tal como em um sistema vetorial de forças, uma resultante, uma solução, será encontrada. Cada sujeito tem que tentar solucionar os conflitos - reais ou imaginários - presentes desde o início da vida, na tentativa de escapar ao sofrimento psíquico: não podemos compreender a particularidade de cada "solução sexual" sem levarmos em conta o equilíbrio singular na dinâmica dos impulsos do sujeito à qual ela responde.

Joyce McDougall (1997) propôs o termo de neossexualidades para pensar algumas soluções encontradas pelos sujeitos, frente a movimentos pulsionais complexos e traumáticos no início da vida. Mais tarde, partindo do pressuposto que a sexualidade é traumática, McDougall traz considerações sobre os conflitos sempre presentes em cada sujeito para pertencer a um gênero, e ser sexuado. A autora se pergunta: "Finalmente, não se poderia propor, então, que a totalidade da sexualidade humana consistiria basicamente de neossexualidades"? (McDougall, 1999, p. 25).

A partir do momento em que os novos arranjos do sexual são ouvidos sem serem teorizados como um desvio em relação aos arranjos "tradicionais" e, talvez o mais importante, sem que nos sintamos ameaçados pelo retorno do recalcado, esses arranjos passam a ser entendidos como uma vicissitude do sexual como outra qualquer: não aquela que responde a normas socialmente estabelecidas e historicamente variáveis, mas aquela que, em sintonia com o mundo interno do sujeito, reapropria e reinventa a polimorfia da sexualidade infantil, em uma relação de objeto.

\section{Referências}

Andrade, E. L. (2017). Psicanálise e educação: contribuições da psicanálise à pedagogia. Divinópolis, MG: Artigo A. Editora Gulliver.

Andre, J. (2016). Nascimento da sexualidade humana. In Sexualidade: três ensaios sobre a teoria da sexualidade. Porto Alegre, RS: Evangraf.

Bagemihl, B. (1999). Biological Exuberance: Animal Homosexuality and Natural Diversity. New York: St. Martin's Press.

Berlinck, M. (1998, set.). O que é psicopatologia fundamental. Rev. Latinoam. de Psicop. Fund., I(1), 46-59.

Berlinck, M. (1999, set.). Catástrofe e representação. Notas para uma teoria geral da Psicopatologia Fundamental. Rev. Latinoam. de Psicop. Fund., II(1), 9-34. 
Bertini, M-J. (2009). Ni d'Eve ni d'Adam - Défaire la différence des sexes. Paris: Max Milo.

Butler, J. (2003). Problemas de gênero - Feminismo e subversão de identidade. Rio de Janeiro, RJ: Civilização Brasileira. (Trabalho original publicado em 1990).

Ceccarelli, P. R. (2007, jun.). Novas organizações familiares: mitos e verdade. Jornal de Psicanálise, 40(72), 89-102.

Ceccarelli, P. R. (2009, set.). Don Quixote e a transgressão do saber. Revista Malestar na subjetividade, $I X(3), 917-937$.

Ceccarelli, P. R. (2012). Mitologia e perversão. In S. Pastori, \& R. Nicolau (Orgs.), Encontro transcultural: subjetividade e psicopatologia no mundo globalizado. São Paulo, SP: Escuta.

Ceccarelli, P. R. (2017a). Sobre a virtualização do sexual. In A. Lopes, C. Barberi, M. Ramos, \& R. Barreto (Orgs.). Conexões virtuais: diálogos com a psicanálise (pp. 157-175). São Paulo, SP: Escuta.

Ceccarelli, P. R. (2017b, dez.). Transexualidades e mudanças discursivas. Estudos de Psicanálise - Belo Horizonte, 47, 151-158.

Ceccarelli, P. R., \& Costa-Salles, A.-C. (2010). A invenção da sexualidade. Reverso, Revista do Círculo Psicanalítico de Minas Gerais, XXXII(60), 15-24.

Eliade, M. (1972). Mito e realidade. São Paulo, SP: Perspectiva.

Fassin, E. (2003, jan.). L'inversion de la question homosexuelle. Revue Française de Psychanalyse. LXVII(1), p. 263-284.

Ferenczi, S. (2011). Thalassa: ensaio sobre a teoria da genitalidade. (2a ed.; Álvaro Cabral, trad.). São Paulo, SP: Martins Fontes. (Trabalho original publicado em 1924)

Foucault, M. (1984). História da sexualidade II: o uso dos prazeres. Rio de Janeiro, RJ: Graal.

Foucault, M. (1985a). História da sexualidade I: a vontade de saber. (6 $\left.{ }^{\mathrm{a}} \mathrm{ed}.\right)$ Rio de Janeiro, RJ: Graal.

Foucault, M. (1985b). História da sexualidade III: o cuidado de si. Rio de Janeiro, RJ: Graal.

Freud, S. (1974a). Totem e tabu. In Edição Standard Brasileira das Obras Psicológicas Completas de Sigmund Freud (v. XIII). Rio de Janeiro, RJ: Imago. (Trabalho original publicado em 1913).

Freud, S. (1974b). Repressão. In Edição Standard Brasileira das Obras Psicológicas Completas de Sigmund Freud (v. XIV). Rio de Janeiro, RJ: Imago. (Trabalho original publicado em 1915).

Freud, S. (1976a). Três ensaios sobre a teoria da sexualidade. In Edição Standard 


\section{ARTIGOS}

Brasileira das Obras Psicológicas Completas de Sigmund Freud (v. VII). Rio de Janeiro, RJ: Imago. (Trabalho original publicado em 1905).

Freud, S. (1976b). Moral sexual civilizada e doença nervosa moderna. In Edição Standard Brasileira das Obras Psicológicas Completas de Sigmund Freud (v. IX). Rio de Janeiro, RJ: Imago. (Trabalho original publicado em 1908).

Freud, S. (1976c). Reflexões para os tempos de guerra e morte. In Edição Standard Brasileira das Obras Psicológicas Completas de Sigmund Freud (v. XIV). Rio de Janeiro, RJ: Imago. (Trabalho original publicado em 1915).

Freud, S. (1976d). O inconsciente. In Edição Standard Brasileira das Obras Psicológicas Completas de Sigmund Freud (v. XIV). Rio de Janeiro, RJ: Imago. (Trabalho original publicado em 1915).

Freud, S. (1976e). Psicologia de grupo e a análise do ego. In Edição Standard Brasileira das Obras Psicológicas Completas de Sigmund Freud (v. XVII). Rio de Janeiro, RJ: Imago. (Trabalho original publicado em 1921).

Freud, S. (1976f). Feminilidade. Novas conferências introdutórias sobre psicanálise. In Edição Standard Brasileira das Obras Psicológicas Completas de Sigmund Freud (v. XXII). Rio de Janeiro, RJ: Imago. (Trabalho original publicado em 1933).

Freud, S. (1987). Neurose de transferência: uma sintese. Rio de Janeiro, RJ: Imago. (Trabalho original publicado em 1915).

Freud, S. (2006). Além do princípio de prazer. In Obras Psicológicas de Sigmund Freud (v. 2). (Trabalho original publicado em 1920).

Freud, S. (2013). As pulsões e seus destinos (Edição Bilingue). In Obras Incompletas de Sigmund Freud. Belo Horizonte, MG: Autêntica. (Trabalho original publicado em 1915).

Freud, S. (2016). O mal-estar na cultura. (Renato Zwick, trad.). Porto Alegre, RJ: L\&PM Editores. (Trabalho original publicado em 1930).

Gregersen, E. (1983). Práticas sexuais: a história da sexualidade humana. São Paulo, SP: Roca.

Krafft-Ebing, R. (1990). Psychopathia sexualis. Paris: Climuts. (Trabalho original publicado em 1895).

Laplanche, J. (1987). Nouveaux Fondements pour la Psychanalyse. Paris: PUF.

McDougall, J. (1997). As múltiplas faces de Eros. São Paulo, SP: Martins Fontes.

McDougall, J. (1999). Teoria sexual e psicanálise. In P. R. Ceccarelli (Org.). Diferenças sexuais. São Paulo, SP: Escuta.

Ramos Estevão, I. (2012, jan-jun.). Retorno à querela do Trieb: por uma tradução freudiana. Cadernos de Filosofia Alemã. 19, 79-106. 
Reis Santos, A., \& Ceccarelli, P-R. (2010). Psicanálise e moral sexual. Reverso, Revista do Círculo Psicanalítico de Minas Gerais, XXXII(59), 23-30.

Roudinesco, E., \& Plon, M. (1998). Dicionário de Psicanálise (Vera Ribeiro, Lucy Magalhães, trad.; supervisão da edição brasileira Marco Antonio Coutinho Jorge). Rio de Janeiro, RJ: Jorge Zahar.

Roudinesco, E. (2015). Puissance de la famille: Edipe, Antigone, Jean Valjean. Le Débat, 183, 129-135.

Tort, M. (2000, juin-juillet-aoüt). Quelques conséquences de la différence «psychanalytique» des sexes. Les Temps modernes, 609, 176-215.

Van Haute, P. (2017, jun.). Lacan encontra Freud? Reflexões patoanalíticas sobre o estatuto das perversões na metapsicologia lacaniana. Lacuna, 3 .

\section{Resumos}

(The sexual, sexuality and its presentations in contemporaneity)

This paper discusses the presentations of the sexual in our contemporary age. First, a brief evolutionary summary of sexuality is given and after that, based on contributions by Freud, Ferenczi and other authors, it describes the unusual paths both the sexual and sexuality have taken in man. The paper further discusses the two dimensions - in a quantum sense of the term - psychoanalysis works with and reveals how instinctive conservatism is repeated still today, although in diverse ways, making the history of man an eternal recurrence. Eventually, the paper depicts how contemporary discourses on sexuality continue to influence cultural sexual morality in their attempts to control sexuality.

Key words: The sexual, sexuality, discourse, contemporaneity

(Le sexuel, la sexualité et ses présentations contemporains)

Cet article porte sur la façon comment le sexuel se présente aujourd'hui. Dans un premier temps, les auteurs fournissent un bref résumé de l'évolution de la sexualité et décrivent de quelle façon, à partir des contributions de Freud, de Ferenczi et d'autres auteurs, le sexuel et la sexualité ont sillonné des chemins inhabituels chez l'être humain. Cet article discute d'ailleurs les deux dimensions, au sens quantique, de la psychanalyse et montrent comment la contemporanéité répète, de façons différentes, le conservatisme pulsionnel, faisant de l'histoire humaine une reprise éternelle. Pour conclure, l'article illustre de quelle manière les discours contemporains sur la sexualité continuent d'influencer la morale sexuelle culturelle dans leurs tentatives de contrôler la sexualité.

Mots clés: Le sexuel, la sexualité, discours, contemporanéité 


\section{ARTIGOS}

(Lo sexual, la sexualidad y sus presentaciones en la actualidad)

El texto discute las presentaciones de lo sexual en la actualidad. Inicialmente, los autores hacen una breve gira evolutiva de la sexualidad y de cómo, a partir de las contribuciones de Freud y Ferenczi, entre otros, tanto en lo sexual como en lo relacionado con la sexualidad, han tomado inusuales caminos en el ser humano. También se discuten las dos dimensiones con las que trabaja el psicoanálisis, en el sentido cuántico, mostrando cómo la contemporaneidad repite, con diferentes copias, el conservadurismo instintivo, haciendo que la historia de los seres humanos sea un eterno recomenzar. Finalmente, se discute la forma en la que los discursos contemporáneos sobre la sexualidad siguen siendo influenciados por la moral sexual cultural en sus intentos por controlar la sexualidad.

Palabras clave: Lo sexual, la sexualidad, discursos, contemporaneidad

(Das Sexuelle, Sexualität und deren Präsentation in der Gegenwart)

Dieser Artikel diskutiert wie sich das Sexuelle in der Gegenwart präsentiert. Zunächst wird die Evolution der Sexualität kurz dargestellt und dann, anhand von Beiträgen von Freud, Ferenczi und anderen Autoren erläutert, welche ungewöhnliche Wege das Sexuelle und die Sexualität des Menschen eingeschlagen haben. Diskutiert werden außerdem die beiden Dimensionen - im quantischen Sinn - mit denen in der Psychoanalyse gearbeitet wird. Es wird aufgezeigt, wie sich der triebhafte Konservatismus heute auf verschiedenen Arten wiederholt und dieser dadurch die Geschichte des Menschen perpetuiert. Abschließend wird dargestellt, wie zeitgenössische Diskurse über Sexualität in ihrer Anstrengung diese zu kontrollieren weiterhin zur kulturellen Sexualmoral beitragen.

Schlüsselwörter: Das Sexuelle, Sexualität, Diskurs, Gegenwart

Citação/Citation: Ceccarelli, P. R., \& Andrade, E. L. (2018, junho). O sexual, a sexualidade e suas apresentações na atualidade. Revista Latinoamericana de Psicopatologia Fundamental, 21(2), 229-250. http://dx.doi.org/10.1590/1415-4714.2018v21n2p229.2.

Editores do artigo/Editors: Profa. Dra. Ana Maria Rudge e Profa. Dra. Sonia Leite.

Recebido/Received: 15.12.2017/ 12.15.2017 Aceito/Accepted: 5.3.2018 / 3.5.2018

Copyright: (C) 2009 Associação Universitária de Pesquisa em Psicopatologia Fundamental/ University Association for Research in Fundamental Psychopathology. Este é um artigo de livre acesso, que permite uso irrestrito, distribuição e reprodução em qualquer meio, desde que o autor e a fonte sejam citados / This is an open-access article, which permits unrestricted use, distribution, and reproduction in any medium, provided the original authors and sources are credited. 
Financiamento/Funding: Os autores declaram não terem sido financiados ou apoiados / The authors have no support or funding to report.

Conflito de interesses/Conflict of interest: Os autores declaram que não há conflito de interesses / The authors have no conflict of interest to declare.

\section{Paulo Roberto Ceccarelli}

Psicólogo; Psicanalista; Doutor em Psicopatologia fundamental e Psicanálise - Universidade de Paris 7 - Diderot (Paris, França); Pós-doutor - Universidade de Paris 7 (Paris, França); Membro da Associação Universitária de Pesquisa em Psicopatologia Fundamental (São Paulo, SP, Br); Sócio do Círculo Psicanalítico de Minas Gerais - CPMG (Belo Horizonte, MG, Br); Sócio-Fundador do Círculo Psicanalítico do Pará - CPPA (Curitiba, PR, Br); Membro da Société de Psychanalyse Freudienne (Paris, França); Professor da Pontifícia Universidade Católica de Minas Gerais - PUC-MG (Belo Horizonte, MG, Br); Professor e orientador de pesquisas na Pós-Graduação em Psicologia/Universidade Federal do Pará - UFPA(Belém, PA, $\mathrm{Br}$ ); Professor e orientador de pesquisas do Mestrado de Promoção de Saúde e Prevenção da Violência/MP, da Faculdade de Medicina da Universidade Federal de Minas Gerais - UFMG (Belo Horizonte, MG, Br); Membro do Programa Antártico Brasileiro Diretor científico do Centro de Atenção à Saúde Mental (CESAME: www.cesamebh.com.br); Coordenador o Instituto Mineiro de Sexualidade (IMSEX: www.imsex.com.br).

Rua Rio Grande do Norte, 355/501

30130-131 Belo Horizonte, MG, Brasil

paulorcbh@mac.com

www.ceccarelli.psc.br

\section{Eduardo Lucas Andrade}

Psicólogo; Psicanalista; membro Fatias de Análise; Palestrante; Diretor do Núcleo de Estudos Psicanálise em Cena; Autor dos livros Psicanálise e educação: contribuições da psicanálise à pedagogia e AMORnheci pensando em nós. Coautor do livro Arte e psicanálise: o ninho. Escritor membro da Academia Bom-Despachense de Letras. Coordenador do IMSEX, sessão Dom Despacho, MG.

Rua Creso Samuel, 973. Bairro Solar.

35603-000 Araújos, MG, Brasil

psicanaliseemcena@hotmail.com

This is an open-access article, which permits unrestricted use, distribution, the original authors and sources are credited. 